\title{
COLLABORATIVE ROBOTS AND KNOWLEDGE MANAGEMENT - A SHORT REVIEW
}

\author{
Flaviu- Constantin MUȘAT Faculty of Engineering, Lucian Blaga University of Sibiu, Romania, \\ flaviu.musat@continental-corporation.com \\ Florin- Constantin MIHU Faculty of Engineering, Lucian Blaga University of Sibiu, Romania, \\ florin.mihu@ulbsibiu.ro
}

\begin{abstract}
Because the requirements of the customers are more and more high related to quality, quantity, delivery times at lowest costs possible, the industry had to come with automated solutions to improve these requirements. Starting from the automated lines developed by Ford and Toyota, we have now developed automated and self-sustained working lines, which is possible nowadays-using collaborative robots. By using the knowledge management system we can improve the development of the future of this kind of area of research. This paper shows the benefits and the smartness use of the robots that are performing the manipulation activities that increases the work place ergonomically and improve the interaction between human - machine in order to assist in parallel tasks and lowering the physically human efforts.
\end{abstract}

Key words: Knowledge Management, Collaborative robots, Improvement, Automotive Industry.

\section{Introduction}

Knowledge management plays a fundamental role in developing an organization, due to its strategy that improves quality of the products, relations with customer, communication inside the organization, reduces product development time. "Although a great deal has been written about the importance of knowledge in management, relatively little attention has been paid to how knowledge creation process can be managed" - Ikujiro Nonaka (1994).

By using knowledge management systems we can improve the usefulness of collaborative robots inside the corporate organizations. This will improve the quality, quantity in a shorter time and with minimal maintenance costs or even unnoticeable.

Related to keeping the competitiveness in the automotive industry, the continuous automation of the production lines is one of the most strategically measures that every company needs to develop. Most of the companies has already automated lines and assembly lines but most recently the direction is more and more related to using the robots for the automated lines. In the last years, collaborative robots were developed related to reducing the weight as much as possible in order to fulfill the tasks and to improve the collaboration with the humans. These robots are sustained by computer vison systems and very sensitive when they are used in the same environment with humans, offering productive flexible solutions.

\section{Knowledge management}

Michael Polanyi classified knowledge into two categories "explicit" knowledge and "tacit" knowledge. Explicit knowledge is articulated, codified and communicated in symbolic and natural language, on the other hand the tacit knowledge is comprised in cognitive and technical elements. The cognitive element refers to an individual mental model consisting of mental maps, beliefs, paradigms and view-points. The technical element refers to concrete know-how, crafts, and skills that apply to a specific context.

Knowledge is created through conversion of tacit and explicit knowledge, this offers us four modes on knowledge conversion: (1) from tacit knowledge to tacit knowledge, (2) from explicit 
knowledge to explicit knowledge, (3) from tacit knowledge to explicit knowledge, and (4) from explicit knowledge to tacit knowledge.

For the first mode, the key to acquiring tacit knowledge is experience, apprentices work with their mentors and learn craftsmanship not through language but by observation, imitation, and practice. In a business, on- the- job training uses the same principle. Without some form of shared experience, it is extremely difficult for people to share each other's thinking processes. This process of creating tacit knowledge is called socialization.

The second mode of knowledge conversion involves the use of social process different types of explicit knowledge. Individuals exchange and combine knowledge through mechanisms such as meetings or telephones. Modern computer systems provide an graphic example. This process of creating explicit to explicit knowledge will be called combination

The third and fourth modes of knowledge conversion relate to patterns of conversion involving both tacit and explicit knowledge. In this cases, this conversion modes capture the idea that tacit and explicit knowledge are complementary and can expand over time through a process of mutual interaction. The interaction involves two different operations: first is the conversion of tacit knowledge intro explicit knowledge, called externalization; second one refers to the conversion of explicit knowledge into tacit knowledge, which is similar to the notion of "learning", this is called internalization.

In 90's Nonaka and Takeuchi developed an framework for knowledge creation inside organizations. This framework combines the above mentioned four ways of knowledge conversion, this model is a continuous interaction between tacit and explicit knowledge.

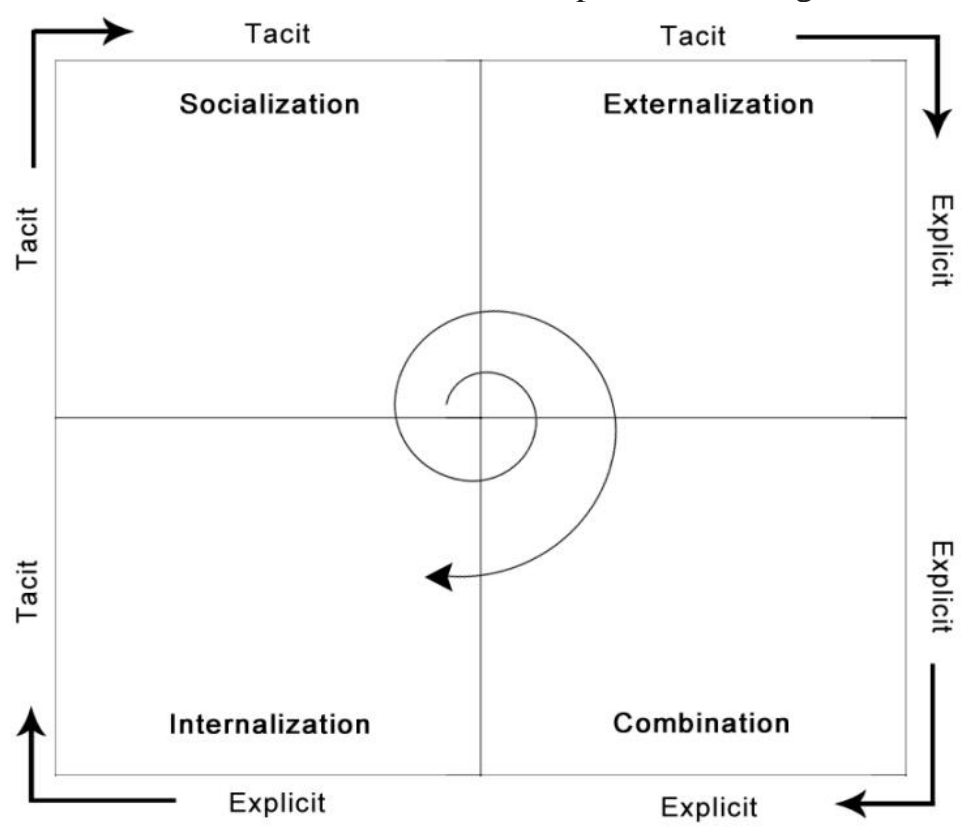

Fig. 1. SECI Model ( Nonaka and Tacheuci)

\section{Collaborative robots used in automotive industry}

The necessity of this paper is that can implement techniques or learning from others' mistakes in the past and avoiding innovations that do not have a purpose or have been invented. You can easily create groups of interest or communities that have access to all persons from a multinational company to the area they are responsible of from their own area of activity. During this work can be done easily and 
defining the role of management development processes and manage these processes in a creative and innovative way both ergonomic and operating in a most efficient and productive at the same time.

As in most multinational companies, the greatest attention and pursued interest is limited to the needs and requirements of the customer, which is why it is a great emphasis on the development and integration processes that are very reliable over time and more efficient from the point of view: capacities, quantities and not least, quality. Also during these projects can track the performance indicators of the desired equipment to be installed and operated on the production line. Having only those devices that meets the best indicators (KPI, Key Performance Indicator) technologies and techniques, can fully meet customer requirements or customer needs.

Along with meeting these requirements and desires of the customer you could earn reputation and trust that can increase both the ability and willingness of the client to continue the project and potential future projects. Just so you remain the first on the list of wished partnership and collaboration with the customer and develop business, globally and to keep your company on top. Only the best qualitative, quantitative, innovative and unbeatable performance indicators is the only way to ensure the success in the global auto industry.

The objective of the theme is to create a stand-alone system capable of being adaptable to any production line or process technology used in a company in the automotive industry. This will be achieved using a programmable robot, capable of performing repetitive tasks and to achieve the movements for all technological process from the line. Going on the idea of quality and cost, this system must be very precise (micrometer precision) and minimal maintenance costs, either predictive or preventive.

The discussions on product quality went from the idea of standardizing the quality concept. All companies in auto motors on the market have had to develop a standard to make it possible to differentiate between customers and manufacturers in the automotive industry. Thus was born this broad concept called product quality. Most of these standards used by renowned brands such as General Motors, Ford and Chrysler are part of the ISO 9000 family, which is spread best leadership model of most companies of this scale.

Quality starts from the simple idea but very important for satisfying customer requirements (customer satisfaction), which will have direct connection with the company's progress or regress if it complies or not this basic idea.

There are several criteria (work requirements) that can concretize the decision to use robots in manufacturing processes and we will see that some of them are also key elements of the industrial robot definition. We remember that (as a rule) it is a mechanism that, by succession of several joints in the cinematographic chain, causes more degrees of freedom at the end of the terminal, the executing one, to which we will entrust the various tasks. But this "sporty" availability will provide the robot with the "labor contract". Otherwise we will identify the work specifications specific to the implementation of robot automation:

- The need to quickly execute a task involving a complex movement (manufacturing / large-scale process);

- Working under heavy conditions from the human perspective (toxicity / pollution, extreme temperatures, radiated electromagnetism - classic examples: steel foundries, paint shops, underground pipeline preparation / refurbishment.

Expected results to this paper is to distribute corporate level know-how acquired in this pilot project and the documentation and how to work with this concept; creating a maintenance plan well thought of our instructions as well as a guide and operating of the equipment. In addition to provide all the data mentioned above are even willing to grant technical and logistical equipment to achieve necessary trainings and use of equipment's in optimum working conditions.

Financial gains in a collaborative manner, even if we are motivated by technological progress, we will not forget that we have to produce car parts. For testing these parts, the collaborative robots are limited to $250 \mathrm{~mm} / \mathrm{s}$. In automatic mode, the robot can reach a maximum speed of $750 \mathrm{~mm} / \mathrm{s}$. As long as Laser Safety Scanners do not detect the presence of any person in the surroundings the cobot 
can move at maximum speed, in this case $750 \mathrm{~mm} / \mathrm{s}$, to load the manufactured parts on a specific place. After the robot places the product in the transport system / desired place, with a 2D articulated camera, it identifies the position of the product in order to place the next piece at maximum speed. The most useful payload on collaborative robots is approximately $35 \mathrm{~kg}$. Cobots have a radius of 1,813 $\mathrm{mm}$ for industrial applications. Meanwhile, more customers in the automotive industry have shown interest in the cobots and have requested information about the areas of use.

Advantages of robots implementation in production are clear to everyone, but it must be understood that the benefits are generated by their efficient programming." Using cobots, companies will get the following benefits:

a. Optimizing time management

b. Increasing the quality of the manufacturing process, accuracy and profitability

c. Increasing the profitability of using production equipment

d. Detecting and solving problems from incipient planning stages - Improve planning capacity

e. Efficiency of data management

f. Improved factory view and advanced 3D modeling

g. Web-based access to all the quality outputs of the production process

The future belongs to self-learning robots that interact with people. The entrepreneur aims to manage future economic growth with robots. Artificial intelligence is one of the most important trends. The concept of deep learning for self-learning machines will be developed in the near future. The concept will be named the IoT (the Internet of Things) and the robots that interact with people - here we are talking about collaborative robots. We also need to think about new materials. (N. "Deep learning" is a series of algorithms that allow machines to learn specific tasks).

In the next five or ten years, one of two robots manufactured and sold will be a collaborative robot. Most of the manufacturers are more optimistic in this regard, saying that collaborative robots will make major advances in 2-4 years. For the development of a robust, high-powered robot, more research is needed than smaller models.

The purpose of this project is the use of the collaborative robots for the actions / specific activities / special movements that for the humans are not recommended to make several them in a repetitive way so many times during the working hours. Besides that, the robots are used for moving heavier components and magazines that for the humans are not ergonomically recommended. Because of this, the use of the cobots is a smart choice for every company that could implement this kind of improvement for the production lines.

The contribution for this project that is still in developing phase (in the incipient phase), is that we managed to make some calculations for the movements of the collaborative robot in the production line. The first step calculates the variables of the joints from Trunk to wrist and the second step calculates the last 2 variables Joints using the method arm - forearm and gripper.

The software system coordinates the movements of the drive axes in the generalized coordinate space to accomplish the displacement load of the pressure device with the object being manipulated between the initial position $(\mathrm{g}+\ldots)$ and the final position (gfi):

THE ORGANIZATION SYSTEM coordinates the movements of the drive axes in the generalized coordinate space to accomplish the displacement load of the pressure device with the object being manipulated between the initial position $\left(\mathrm{g}+_{-}\right)$and the final position $(\mathrm{gfi})$ :

$\mathrm{G}(\mathrm{t})=\mathrm{gi}+\mathrm{r}(\mathrm{t})(\mathrm{gf}-\mathrm{gi}),(1)$

Where $\mathrm{r}(\mathrm{t})$ represents the interpolation function;

$\mathrm{r}(0)=0$ and $\mathrm{r}(\mathrm{t})$, (2)

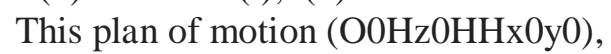

Is obtained using the projection H-PS to the center of the gripper like this:

On the $\mathrm{x} 0 \mathrm{y} 0$ the pr.xOyOH=HxOy0

And on the axis $\mathrm{z} 0$ the pr.zOH=HzO

This describes the desired position of the gripper, $\mathrm{H}(\mathrm{px}, \mathrm{py}, \mathrm{pz})$. 
The parameters D-H of the model are known, a1, a2,a3,d1,d5 and lTOOL.

The position vector from the shoulder to the wrist, $\mathrm{SW}$, is obtained by projecting the point $\mathrm{S}$ (origin $\mathrm{SC}$ to shoulder joint and $\mathrm{W}$ - origin of SC Joint wrist) on the lines $\mathrm{OHxOyO}$ and $\mathrm{OHzO}$

The operational coordinate that expresses the absolute flexing angle of the hand (the angle of the hand with the horizontally plan $\mathrm{x} 0 \mathrm{y} 0$ ).

Using the cosine theorem:

PR2+ PZ2 $=\mathrm{a} 22+\mathrm{a} 23-2 \mathrm{a} 2 \mathrm{a} 3 \cos (\pi-\theta 3),(4)$

Results the angle desired of the arm and gripper.

\section{Conclusions}

This paper is related to a project that is in the beginning phase, meaning that this utility of this project will be developed in the future.

As a conclusion of this paper is that if you want to cope the customer requirements: quality, quantity and Key Performance Indicator you need to make continuous improvements on your equipment's and this is possible only using collaborative robots and a adequate knowledge management in order to fulfill the customer needs.

A knowledge management system must be created related to the customer expectations and needs in order to have a high level of knowledge and satisfaction inside the organization. Nevertheless, to have a pleasant knowledge creation it can be developed a special community in order to share and train the information to all people interested in using cobots. A good KMS can be the success in avoiding previous mistakes and helping employees develop faster.

\section{References}

1.Schröter, D., Jaschewski, P., Kuhrke, B., \& Verl, A. (2016). Methodology to Identify Applications for Collaborative Robots in Powertrain Assembly. Procedia CIRP, 55, 12-17.

2.Alavi, M., \& Leidner, D. E. (2001). Review: Knowledge management and knowledge management systems: Conceptual foundations and research issues. MIS quarterly, 107-136.

3.De Brito, M. F., Da Costa Figueiredo, R. M., Venson, E., Dias Canedo, E., Junior, M. R., \& Carlos, L. (2017, January). Knowledge Transfer in a Management Process for Outsourced Agile Software Development. In Proceedings of the 50th Hawaii International Conference on System Sciences.

4.Nonaka, I. (1994). A dynamic theory of organizational knowledge creation. Organization science, 5(1), 14-37.

5.NICOLAESCU, S. Ş., \& Kifor, C. V. (2014). Knowledge Management in Automotive Industry-Steps and Customer Focus. Quality-Access to Success, 15(143).

6.Gorry, G. A. (2016). Memory machines and the future of knowledge management. Knowledge Management Research \& Practice, 14(1), 55-59.

7.Bhatt, G. D. (2001). Knowledge management in organizations: examining the interaction between technologies, techniques, and people. Journal of knowledge management, 5(1), 68-75.

8.Lee, H., \& Choi, B. (2003). Knowledge management enablers, processes, and organizational performance: An integrative view and empirical examination. Journal of management information systems, 20(1), 179-228.

9.Guo, Y., Parker, L. E., \& Madhavan, R. (2004, January). Towards collaborative robots for infrastructure security applications. In Proceedings of International Symposium on Collaborative Technologies and Systems (Vol. 2004, pp. 235-240).

10. Surdilovic, D., Schreck, G., \& Schmidt, U. (2010, June). Development of collaborative robots (cobots) for flexible human-integrated assembly automation. In Robotics (ISR), 2010 41st international symposium on and 2010 6th German Conference on Robotics (ROBOTIK) (pp. 1-8). VDE. 